\title{
La representación del espacio doméstico en cinco poetas de América Latina
}

\author{
Mental picture of the domestic atmosphere \\ in five Latin American poets
}

\author{
Leisie Montiel Spluga*
}

\section{Resumen}

El presente trabajo tiene como propósito cotejar algunos poemas referidos a la vida doméstica, desde la perspectiva de cinco poetas latinoamericanas: María Calcaño, Rosario Castellanos, Lydda Franco Farías, Piedad Bonnet y María Mercedes Carranza. Tal ejercicio de lectura se hace a la luz de fundamentos teóricos tomados de Lily Litvak (Erotismo fin de siglo), Nancy Armstrong (Deseo y ficción doméstica, una historia política de la novela), Nora Domínguez y Carmen Perilli (Fábulas del género), entre otros referentes biblio-hemerográficos cuyos aportes se vinculan con la construcción de elementos poéticos que convergen en la recreación de la casa como espacio privado. Las experiencias de vida, los objetos personales, los sentimientos y las labores cotidianas suelen ser hilos recurrentes que nos permiten llegar a concluir que el modo de ordenamiento de los mismos refleja los distintos tipos de comportamiento conformadores de la identidad compleja de la mujer latinoamericana. Dicha complejidad se mueve entre un tiempo presente y una tradición que fungen como directrices en la poética de las autoras arriba nombradas. Bien sea acatando las tradiciones o rebelándose contra ellas, las cinco poetas asumen-desde su tiempo presente-la postura que más se aviene con sus intereses y expectativas, de tal manera que obtenemos como resultado la aparición de voces sinónimas donde se alojan dos constantes: una sabiduría y una sensibilidad refinadas hasta el punto de reinterpretar la cotidianidad y el sentido común como asuntos susceptibles de ser poetizados.

Palabras clave

Vida doméstica, poesía, casa, cotidianidad.

Abstract

The purpose of this paper is to compare some poems, which refer to domestic life from the perspective of five Latin American poets: María Calcaño, Rosario Castellanos, Lydda Franco Farías, Piedad Bonnet y María Mercedes Carranza. This reading is done based on the theoretical fundamentals taken from Lily Litvak (Erotismo fin de siglo), Nancy Armstrong (Deseo y ficción doméstica, una historia política de la novela), Nora Domínguez y Carmen Perilli (Fábulas del género), among other biblio-hemerographical references that contribute to the construction of poetic elements that coincide on the recreation of home as a private realm. Life experiences, personal objects, feelings and daily tasks are usually recurrent threads that allow us to conclude that the way in which they are organized reflect the different types of behaviors that make up the complex identity of Latin American women. This complexity moves between present time and a tradition that act as guidelines in the poetry of the writers mentioned above. Whether these poets obey traditions or they revel themselves against them, they take a stand from their present time that more agrees with their interests and expectations. Therefore, we obtain as a result the appearance of synonymous voices where two constant features remain: wisdom and a sensitivity refined up to the point of reinterpreting daily life and common sense as susceptible issues to be poeticized.

\section{Keywords}

Domestic life, poetry, house, daily life.

Artículo recibido el 22 de abril de 2008 y aprobado el 14 de noviembre de 2008.

* Montiel Spluga, L. La representación del espacio doméstico en cinco poetas de América Latina. Universidad del Zulia, Facultad de Humanidades y Educación. Escuela de Letras.

Correo electrónico: leisie.montiel@gmail.com y leisiemontiel@yahoo.com. 
La esfera de lo cotidiano, que es también la esfera de la aparente subordinación, está circunscrita por un límite más allá del cual surge el momento extraordinario, apocalíptico y atemporal de un mundo al revés.

Partha Chatterjee

\section{Introducción}

El propósito central de este artículo es cotejar las posturas que adoptan cinco grandes poetas de América Latina frente a la vida doméstica y su representación. Ellas son: María Calcaño (Maracaibo, 1906-Caracas, 1955), Rosario Castellanos (Ciudad de México, 1925-Tel-Aviv, 1974), Lydda Franco Farías (Sierra de San Luis, Falcón, 1943-Maracaibo, 2004), María Mercedes Carranza (Bogotá, 1945Bogotá, 2003) y Piedad Bonnet (Amalfi, 1951). En primera instancia, me interesa destacar el discurso que generan todas ellas, desde el código poético, en relación con el tema que las emparenta -lo doméstico- para luego vincularlo a algunos trabajos de crítica y teoría literarias afines a su propuesta estética. En tal ejercicio de lectura, me orientaré desde la luz de fundamentos teóricos -así como de intuiciones- tomados de Lily Litvak (Erotismo fin de siglo), Nancy Armstrong (Deseo y ficción doméstica, una historia política de la novela), Nora Domínguez y Carmen Perilli (Fábulas del género), entre otros referentes biblio-hemerográficos cuyos aportes se vinculan con la construcción de elementos poéticos que convergen en la recreación de la casa como espacio privado.

¿Cuáles son las directrices que determinarán el rumbo de esta investigación? Las experiencias de vida, los objetos personales, los sentimientos y las labores cotidianas, ya que todos ellos circulan como hilos recurrentes que nos permiten llegar a concluir que el modo de ordenamiento de los mismos refleja los distintos tipos de comportamiento conformadores de la identidad compleja de la mujer latinoamericana. Dicha complejidad se mueve entre un tiempo presente y una tradición que fungen como hitos en la poética de las autoras arriba nombradas. Bien sea acatando las tradiciones o rebelándose contra ellas, las cinco poetas asumen -desde su tiempo presente- la postura que más se aviene con sus intereses y expectativas, de tal manera que obtenemos como resultado la aparición de voces autónomas -y sinónimas- en las que se alojan dos constantes: una sabiduría y una sensibilidad refinadas hasta el punto de reinterpretar la cotidianidad y el sentido común como asuntos susceptibles de ser poetizados. La maestría con que ellas asumen su oficio, al decantar el peso que las palabras tienen según el contexto vital de cada una, revela la expresión trascendente -y, en mi opinión, difícilmente superable- de cinco intérpretes del papel cotidiano que las mujeres latinoamericanas desempeñan, en combinación con su afición intelectual más ferviente o, como bien lo dijera el poeta cumanés Gustavo Pereira, con el sino de haber elegido como opción de vida "el peor de los oficios", tan tremendamente mal pagado, como amas de casa.

\section{Fundamentos teóricos del corpus poético estudiado}

Esa doble vertiente existencial que señalaba anteriormente -el ejercicio simultáneo de la sabiduría y la sensibilidad-calza, de modo coherente, con las ideas que expone Nancy Armstrong cuando define al sujeto moderno en un trabajo suyo destinado a indagar sobre el importante papel que la mujer inglesa tuvo para la formación -primero en la ficción, en las novelas- de lo que sería la clase media. Dice Armstrong: "Este nuevo modelo de mujer -la mujer doméstica, 'reina del hogar' - no constituyó simplemente un modelo de feminidad, sino que acabó convirtiéndose en el modelo de subjetividad para el individuo moderno, producto de la cultura burguesa en formación" (Armstrong, 1987: 9, énfasis de la autora).

Resulta interesante observar las "competencias" o funciones que Armstrong destaca al caracterizar la unidad doméstica descrita por los tratados puritanos, pues, sin lugar a dudas, ese repartimiento pensado desde una razón masculina de corte patriarcalista subyace en la atención puesta por Calcaño, Castellanos, Franco, Carranza y Bonnet cuando elaboran sus respectivos códigos poéticos para responder a distintas inquietudes que las man- 
comunan. Tal lista de tareas citada por Armstrong es la siguiente:

\section{Marido Mujer}

Conseguir bienes Reunirlos y ahorrarlos

Viajar, ganarse la vida Llevar la casa

Ganar dinero y provisiones No derrocharlos

Tratar con muchos hombres Hablar con pocos

Ser “animador” Ser solitaria y retraída

Saber hablar Presumir de silencio

Ser dadivoso Ser ahorradora

Presentar el aspecto que guste Arreglarse como conviene

Ocuparse de todo fuera de casa Supervisar y ordenar en el hogar (p. 33).

Desde una actitud serena o irreverente, las poetas escriben y, de este modo, reaccionan a los dictámenes del "deber ser" según el género que se trate; a pesar de hallarse a una gran distancia temporal del momento en que surgieron los tratados puritanos, ellas deben enfrentarse a normas aún vigentes, como las enunciadas por Armstrong. Aún cuando nos encontramos en una cultura globalizadora cuya velocidad tecnológica nos obliga a replantearnos dichas funciones domésticas y extradomésticas, la mujer moderna tiene que lidiar, aún, con un cíclope en el que moran los prejuicios, los tabúes y los recelos. Pero el ojo agudo de Armstrong nos invita a leer, con mayor profundidad, lo que hay debajo de ese aparente acatamiento de fórmulas domésticas en las que no era de esperarse que ocurriera ninguna transgresión:

El hogar había de ser gobernado por una forma de poder que era esencialmente femenina -es decir, esencialmente distinta de la del hombre y, con todo, una fuerza positiva por derecho propio. Aunque sin duda sujeto de la fuerza política, la mujer doméstica ejerció una forma de poder que pareció no tener fuerza política en absoluto porque parecía poderosa sólo cuando era deseada. Era el poder de la vigilancia doméstica (p. 35).
Lily Litvak, por su parte, elabora unos planteamientos bien iluminadores a la hora de precisar el condicionamiento patriarcalista que se ha ejercido sobre la mujer en la cultura occidental:

El dominio emocional que ejercen los padres sobre las hijas, el estrecho concepto del lugar que debe ocupar la mujer en la familia y el miedo a "lo inmoral". Todo combinaba en una tendencia social para destituir a la mujer de su personalidad y a relegar a la joven casadera a una clase con características comunes, sin individualidad ni deseos propios (Litvak, 1979: 185).

Pero con Armstrong hemos visto que el espacio privado que supone la casa se subvierte porque se politiza, porque en él ocurren intercambios de ideas sobre lo que acontece "afuera". Como bien lo puntualiza la crítica Francine Masiello, "defender un modo estético que pone de manifiesto las crisis y fisuras del actual molde social [equivale a buscar] las políticas del texto" (1997: 14).

De este modo, esa vieja expresión popular invocada por Litvak de "la mujer en casa y con la pata rota" ha quedado muy atrás cuando nuestras poetas exploran, con profundidad, el ámbito doméstico y lo hacen estallar en conexiones impensables para la pronta, ligera y rezagada mentalidad -tan extemporáneamente- patriarcalista. Así como el hogar puede convertirse en un espacio de fruición y de indagación sensual -lo veremos con Calcaño-, también cabe ser leído como una zona en reclamación -lo veremos en las demás- donde la ironía, el sarcasmo, la parodia, el ingenio y otros recursos discursivos se apoderan de la palabra y la convierten en un arma de gran filo. Arma que sirve para cortar con la tradición o rebanarla, de acuerdo con la intención particular de cada poeta y su peculiar manera de apropiarse simbólicamente del mundo, a fin de cuestionarlo. Es decir, más que producir "paraísos artificiales", "torres de marfil" u otro tipo de territorios ajenos al entorno inmediato, el grupo de cinco voces latinoamericanas que he escogido muestran, con suficiente fuerza, que escribir poesía consiste en hilvanar símbolos que expresan una actitud crítica ante la vida y, muchas veces, las posibles soluciones 
o salidas a diversas crisis del momento. Tal como lo precisa Masiello, "el dominio simbólico puede trazar alternativas para la sociedad civil y articular determinadas preocupaciones sobre las crisis del presente" (1997: 13).

Por último, no me queda sino pasar a la siguiente fase de esta investigación: la de desgajar el corpus poético propuesto, con miras a armar un arte poética de lo doméstico poniendo a dialogar los textos, para que unas poetas terminen por decir lo que otras apenas dejaron entrever.

\section{María Calcaño}

Aunque la obra poética de María Calcaño ha sido rescatada, sobre todo, por un tono erótico que para la época en que le tocó vivir lucía atrevido; era el momento de un grupo literario zuliano que ella conoció, la generación del grupo Seremos, según nos lo comenta el crítico Cósimo Mandrillo: "A pesar de que ella no perteneció nunca a Seremos, mantuvo un estrecho contacto con ese grupo literario a través de Héctor Araujo Ortega [su marido]" p. 25. El último de sus libros publicados, Entre la luna y los hombres (1961) nos revela a una mujer que se siente realizada en su papel de ama de casa, feliz de cumplir con las tareas "propias de su sexo". Esta actitud de vivir mágicamente su papel de ama de casa llama la atención para una época (estamos hablando de los años veinte y treinta) en la que todavía la mujer se sentía marginada en muchos sentidos, sobre todo en los espacios donde no sólo pudiera ejercitar su inteligencia, sino, también, donde ésta fuese reconocida indistintamente por hombres y mujeres. De este modo, la poeta logra capturar ese "momento extraordinario" anunciado por Partha Chatterjee en el epígrafe que abre este trabajo. Lilia Boscán lo define muy bien:

En una ciudad provinciana, como era Maracaibo en los años treinta, sería un escándalo que una mujer se atreviera no sólo, [sic] a ser escritora sino a desnudarse íntimamente como lo hace esta autora. Su rebeldía provocadora debió parecer un insulto a la sociedad conservadora de la época que tenía muy claro los roles de la mujer (1998: 73).
Boscán reafirma el papel marginal que se le ha destinado a la mujer, aún cuando se trate de "profesionales exitosas", como bien lo apunta la ensayista. Destaca la situación de minusvalía intelectual que se le ha querido atribuir, sobre todo, para salvaguardar los intereses prácticos del sector masculino: "Subestimada intelectualmente, la mujer sólo servía para ama de casa y madre. Era la responsable del hogar y se le negaban otras aspiraciones" (p. 73).

Dice Luis Suardíaz en su ensayo "María Calcaño, la radiante desconocida":

Mientras las revistas culturales y los grupos juveniles resultan de gozo ante las vanguardias y surgen universidades, activísimas organizaciones obreras, partidos políticos que se pronuncian por una mayor participación del ciudadano en la vida pública, la mujer sigue oculta en su rincón. No abriendo la rosa y cerrando el clavel como la Ana de los cantos infantiles, sino zurciendo, lavando, trajinando entre golpeadas cacerolas y a veces soñando con amantes imposibles, mientras cuida niños propios o ajenos y descubre a los cuarenta años que es una prematura anciana que nunca conoció las mieles de la juventud (Suardíaz, 1999: 32).

En el prólogo de la antología poética que aquí se examina, Mandrillo señala que Calcaño puede ser definida $-y$ aquí se vale de un término acuñado por José Ramón Medina- como una poeta “neoromántica”. Al respecto, apunta que “[é] ste neoromanticismo de María Calcaño [...] reivindica la cotidianidad como materia poética" (p. 42; énfasis mío).

La combinación de irreverencia y sumisión que apreciamos en Calcaño pone en evidencia una compleja convivencia de actitudes para enfrentar las distintas experiencias de vida por las que atraviesa la poeta, muy a tono con su voluntaria inclinación hacia la fruición de la palabra dicha o escrita que la dotan de existencia. Dos son los poemas que delatan su simbiosis con la vida doméstica: "Echo a volar tus camisas" y "Poema de mi casa de cuatro gradas". En el primero de ellos, asistimos a la plenitud vivenciada por una mujer que se siente feliz al ver tendidas las camisas que le ha lavado a su amado, porque en ellas cree encontrar la prolongación de su 
cuerpo. Así, una faena rutinaria como la de lavar es capaz de generar una mágica experiencia en la que se esperaría el tedio. Veamos el poema completo:

En las ramas de un naranjo echo a secar tus camisas...

¡Qué alegre amanece el patio

de la casa!

Lindo está mi asoleadero

cuando lavo.

Como si tuviese alas

con tus camisas tendidas.

Las hojas se ponen húmedas

y las camisas retozan.

Un saludo de mar verde

por un adiós de pan blanco...

Son tus camisas de fiesta,

tus camisas de trabajo,

con agudos alfileres

sostenidas en el aire.

Brillando de puro blancas,

calle arriba, calle abajo,

por todas partes te llevan...

Yo te aguardo.

La noche siempre está hermosa.

¡Qué alegre amanece el día

en mi patio! (Calcaño, 1983: 159-160).

El segundo poema enunciado nos vuelve a presentar a una mujer que se siente feliz de tener una casa que, aunque es más pequeña que las casas vecinas, la colma de muchas satisfacciones domésticas debido a que se desborda en calor de hogar, fertilidad (hay tres hijas), pulcritud y cuidado. Parecería que la lección por aprender fuera ésta: saber llevar una casa implica ser vigilantes de su orden y limpieza. De nuevo transcribimos, por completo, el poema:
No tiene balcones mi casa.

Entre las otras,

altas, serias,

casi deshabitadas,

es como una muchacha estrepitosa

riendo.

¡Qué alegre estoy con mi casa

de cuatro gradas!,

con muchos postigos

y de rojo pintado el alero.

Y un gran patio asoleado

y tres niñas alegres y hermosas

haciendo nacer el día

en mi pedacito de mundo.

Enfrente el polvo agobia

los viejos caserones olvidados.

En mis matas las rosas

dan una gracia viva.

El mantel en mi mesa

brilla de puro blanco.

Y relucen al sol

los pasadores negros.

Para saber si soy feliz

sólo tengo que mirar

la fachada inmóvil

de la casa de enfrente (pp. 167-168).

En ambos textos se percibe una actitud festiva -hedonista, en palabras de Boscán- hacia un campo de experiencia -el de la vida doméstica- que, lejos de empobrecer espiritual e intelectualmente a la poeta, la eleva hacia una dimensión en la cual la sensibilidad, la sensorialidad y la inteligencia se activan de tal modo que el lenguaje, en sí, se convierte, al mismo tiempo, en objeto deseado y en medio de satisfacción del deseo. Afirma Boscán: "[1]a cotidianidad abrumadora se desvanece en el tejido de versos claros y frescos por el que corren raudos sus pensamientos 
y emociones" (Boscán, 1998: 72). También anota la ensayista que "[1]a vida y obra de María Calcaño es la afirmación de la mujer inteligente y sensible, que en medio de la cotidianidad ennoblece el vivir y lo dignifica rompiendo ataduras sociales y lingüísticas, fiel a sí misma y a su sentir, derramándose íntimamente en amor, vida y poesía” (p. 75). ¿A qué se debe -nos preguntamos- que una mujer nacida en un tiempo y en un espacio hostiles para su inclinación hacia la palabra sea capaz de hallar la felicidad, aún en el encierro de la casa, la cárcel "natural" adonde ha sido confinada desde hace siglos? Creo que la respuesta a esta interrogante la proporciona Boscán cuando toca una palabra que es piedra angular: la libertad. Así, de la poeta nos comenta que "es libre para recrear en la poesía los momentos de íntima felicidad y para comunicar sus más profundas reflexiones sobre la vida y sobre la muerte" (p. 74). Al adoptar esta postura vital, Calcaño nada a contracorriente de los preceptos pensados para controlar las funciones femeninas, las cuales son analizadas por Mariluz Domínguez en los siguientes términos:

[A] pesar de que en las sociedades occidentales prevalecen principios formales de libertad e igualdad, se desarrollan procesos que simbólicamente devalúan lo culturalmente femenino, y se propicia que los sujetos -bien a través del currículum oculto, bien de los medios de comunicación, bien de prácticas familiares, laborales, de participación social, etc. - interioricen los estereotipos de género (Domínguez, 2007: 23).

No es la de Calcaño, entonces, una actitud bobalicona, de mujer "corta de ideas", sino, por el contrario, la de quien ha alcanzado tal madurez espiritual que cualquier norma o restricción termina por desplomarse ante la fuerza avasalladora de su don poético. Calcaño está convencida de que para que su espíritu libre trascienda debe saber lo que es amar, tener hijos y debe, ante todo, escribir poesía: "María Calcaño [agrega Boscán], existencialista atormentada, se aferra al amor como única certeza de vida, se prolonga en los hijos, pero la poesía la hace eterna y la saca del olvido" (Boscán, 1998: 79).

Como comentaba más arriba, con su actitud de sumisión doméstica se conjuga una pulsión erótica que leemos en versos como los siguientes, tomados de su primer libro Alas fatales (1935): "Carne... ¡Carne mía!,/ intensamente llama,/ intranquila, poseedora:/ ¡abre! / Tú eres como un jardín...” (Boscán, 1998: 63-64). Mandrillo capta, con detalle, ese elemento transgresor:

Es muy difícil que la mentalidad conservadora de sus contertulios viera con buenos ojos aquel intento de ruptura formal [ni modernista ni parnasianista] que era la poesía de Calcaño. Por otra parte, el desafío debía ser peor aún por cuanto la poetisa escoge una materia más que escabrosa para la época y la ciudad: el erotismo (p. 26).

Más adelante, el crítico nos refiere cuál es la intención de la poeta cuando elige trabajar con dicha materia: "golpear al lector moralista y pacato de su tiempo" (p. 48), pues, como él mismo lo ha manifestado, "María Calcaño estaba fuera de su contexto. Vivió con varios años de adelanto a su ciudad" (p. 27). Véase este otro poema titulado "La toma", cuyo tono erótico es abundante y de gran logro en la construcción de las imágenes:

¡Me trepan las raíces
de tus manos amadas
y arropada en caricias
ya casi no me veo!

Me saltaste tan sólo

la blancura serena;

seguros de la noche

me moldearon tus brazos,

y fue un enredo fácil

la fiesta inagotable.

¡Hombre partido en cien

que me fuerzas la vida!,

en mis pechos desnudos

desata tu rudeza,

para que tengan ellos

ese duro barniz

que les falta de hombre (p. 65). 
En este poema vemos perfectamente que el erotismo se manifiesta con una fuerza hiperbólica creada a partir de imágenes labradas con mucho movimiento y del uso de recursos de énfasis como los signos de exclamación. Este tono, mucho más cercano a la irreverencia de quien no se conforma con los eventos rutinarios - "expresión de una angustia profunda”, como diría Boscán-, es el otro lado de la moneda que no debemos pasar por alto a la hora de graduar el temperamento poético de Calcaño, mujer-miríada, mujer facetada en esposa, madre y poeta: tres ángulos que, al entrecruzarse, dejan entrever una identidad compleja y, por ello, auténtica.

\section{Rosario Castellanos}

De Rosario Castellanos son muchos los poemas que pudiéramos citar a propósito del tema estudiado, pero el que más me seduce por su completitud en cuanto al sentido personal de la existencia es el titulado "Economía doméstica". Lo transcribiré también entero porque además de contener una suerte de "alfabetización doméstica" (las reglas de oro heredadas de la madre en lo que tiene que ver con la compostura del hogar), lleva en sí otro tipo de pulsión desintegradora de la total docilidad, tal como vimos que sucede en el caso de la poeta Calcaño cuando doma la palabra con imágenes eróticas, atendiendo más -como apunta Patricia Valenzuela- a la necesidad que a la arbitrariedad del signo: "El signo arbitrario concebido por los lingüistas se transforma, en manos del poeta, en el signo necesario que diga, más allá del sistema de referencias establecido, lo indecible" (Valenzuela, 1998: 19, énfasis de la autora). Leamos, entonces,

"Economía doméstica":

He aquí la regla de oro, el secreto del orden: tener un sitio para cada cosa

$\mathrm{y}$ tener

cada cosa en su sitio. Así arreglé mi casa.

Impecable anaquel el de los libros:

un apartado para las novelas,

otro para el ensayo

y la poesía en todo lo demás.
Si abres una alacena huele a espliego

y no confundirás los manteles de lino

con los que se usan cotidianamente.

La ropa en su cajón correspondiente

y los muebles guardando las distancias

y la composición que los hace armoniosos.

Naturalmente que la superficie

(de lo que sea) está pulida y limpia.

y es también natural

que el polvo no se esconda en los rincones.

Pero hay algunas cosas

que provisionalmente coloqué aquí y allá

o que eché en el lugar de los trebejos.

Algunas cosas. Por ejemplo, un llanto

que no se lloró nunca;

una nostalgia de que me distraje,

un dolor, un dolor del que se borró el nombre,

un juramento no cumplido, un ansia

que se desvaneció como el perfume

de un frasco mal cerrado.

Y retazos de tiempo perdido en cualquier parte.

Esto me desazona. Siempre digo: mañana...

Y luego olvido. Y muestro a las visitas,

orgullosa, una sala en la que resplandece

la regla de oro que me dio mi madre

(Castellanos, 2002: 107-109).

Pero aquí, con la poesía de Castellanos, dicha pulsión es la del interés intelectual, la de la posesión de la palabra para ser más allá del espacio cerrado que implican las paredes físicas del recinto doméstico, dentro del cual la poeta se desempeña como una perfecta ama de casa que acoge con ¿ironía? las lecciones más elementales del orden y la limpieza. "Mis intereses extradomésticos han sido literarios y, al través de ellos, políticos", declarará la autora según nos comenta Raúl Ortiz y Ortiz, su ex compañero de 
la Cátedra de Literatura Comparada en la Facultad de Filosofía y Letras de la Unam. De allí que María Luisa Gil Iriarte -apoyándose en Maureen Ahernafirme que:

Las voces de la obra de Rosario Castellanos exploran un mundo de mujer a lo largo del espacio doméstico, usado como laboratorio de creatividad, subvirtiendo los símbolos, diciendo lo indecible, usando el cuerpo como semillero simbólico, vislumbrando el poder opresor del lenguaje, convirtiendo los juegos de palabras en poesía (Gil, 1996: 79-80).

Todas estas operaciones, ejecutadas a contrapelo de lo que dictan el sentido común y los comportamientos condicionados por el orden patriarcalista al que se adscribe la mayor parte de los hogares latinoamericanos, revelan un proyecto poético personal que necesita fundarse sobre nuevas bases culturales para poder hacerse de un espacio discursivo autónomo. Por eso, Gil Iriarte considera que la poeta mexicana lleva a cabo una tarea que rebasa sus intereses particulares, pues llega a representar a todo un sector -el de las mujeres- ávido de conquistar nuevas y más eficaces posibilidades de expresión:

[L]a tarea, iniciada a partir de los años setenta por las escritoras hispanas, de revisión cultural, de reformulación de mitos, el deseo de redefinir la coordenada exacta de la mujer dentro del espacio social, había sido ya emprendida en México por nuestra autora en 1948, con la aparición de su primer libro de poemas (Gil, 1996: 80).

En su poesía, Castellanos dota de un nuevo significado a la función esencial que la razón masculina de Occidente le adjudica a la mujer: la de la maternidad. Así, en vez de "alumbrar" hijos de carne, da a luz (a la luz pública) sus textos, tal como lo haría en su tiempo Sor Juana Inés de la Cruz. En este sentido, Gil Iriarte apunta que "[Rosario Castellanos] [o]bservó ese segundo sexo en sus relaciones con el mundo y del primer y perdurable interés por lo femenino, no ya como esencia, sino

1 Cfr. de De Beauvoir, S. (1999). El segundo sexo. Buenos Aires: Sudamericana. como vivencia, resultaron ensayos, novelas, piezas teatrales y poemas” (Gil, 1996: 79, énfasis mío). Más adelante agrega: "[1]a negación de la maternidad puede verse, entonces, como una negación del rol social, al tiempo que constituye una afirmación del derecho a perpetuarse a través de la palabra" (p. 81). Este comentario lo hace Gil a propósito del siguiente poema de Castellanos:

De la vigilia estéril

Todos los muertos yacen en mi vientre.

Montones de cadáveres ahogan en

indefenso

embrión que mis entrañas niegan y

desamparan.

No quiero dar la vida.

En una ocasión, Castellanos le escribe de Tel-Aviv a Maureen Ahern acerca de su propia experiencia sobre la vida doméstica: "Mi creencia de que los asuntos domésticos deben compartirse, fue totalmente inoperante durante el tiempo (trece años) que duró mi matrimonio" (cfr. el prólogo del poemario que aquí se cita, pp. 13-14, cuyo autor es Ortiz y Ortiz). En los versos finales de "Autorretrato", la poeta vuelve a aludir a la influencia que el ambiente doméstico ejerce en su proyecto escritural, pues nos dice: “y no lloro en la cámara mortuoria / ni en la ocasión sublime ni frente a la catástrofe. / Lloro cuando se quema el arroz o cuando pierdo / el último recibo del impuesto predial" (Castellanos, 2002: 127). De este modo, Castellanos resume -con la serena indulgencia de quien se mira reaccionar frente a los eventos cotidianos de la vida- uno de los focos de los que provendrán sus batallas campales contra la incomprensión por su afán creador: el hogar que carece de un interlocutor capaz de ponerse en sus zapatos. Así lo delata su poema "Valium 10":

Y ya en la oscuridad, en el umbral del sueño, echas de menos lo que se ha perdido:

el diamante de más precio, la carta 
de marear, el libro

con cien preguntas básicas (y sus correspondientes respuestas) para un diálogo

elemental siquiera con la Esfinge (pp. 72-73).

\section{Lydda Franco Farías}

Si eligiéramos como rumbo para esta investigación marcar un tono subterráneo que circula como las llamas de un volcán que buscan hacer erupción, seguramente el momento poético más apropiado para ubicar ese estallido sería el poema inicial del libro Una (1985), de Lydda Franco Farías. Más allá del tono veladamente irónico con que Rosario Castellanos asume los oficios del hogar, Franco opta por rebelarse contra ellos sin rodeos y autorizarse a gozar de un espacio para el ocio. Sólo transcribiré la primera parte, porque con esta muestra poética basta para medir la algidez, la irreverencia y el ingenio con que se resuelve cada verso:

¿estás oyendo cama el edicto de mi pereza? voy a desayunarme la claraboya de la mañana voy a atragantarme periódico con tus crónicas violentas

voy a tener noticias del mundo hasta la ingesta

de par en par ventanas

muéstrenme lo que sin mí despierta

sacúdete ropa inmunda los dobleces

espanta con lejías la penumbra

soliviántate plancha

aplasta en un desliz las pérfidas arrugas

a volar escoba sin bruja que respire el polvo

dancen muebles al ritmo que los aviente

púlete piso en redención de no empañado espejo

arde sin paz cocina del infierno

tápate olla impúdica

cuece a la sazón luego evapórate

suenen cubiertos en estampida muda

a fregarse platos les llegó su hora

la carta por favor

quiero probar el albedrío

niños culpables aúllenle a la luna

no estoy de humor para lidiar con monstruos

que no amor que no

la señora hoy decidió estar indispuesta

(Franco, 2002: 83).

Franco se sirve del humor más negro para desahogarse del hastío, de la obstinación a que la llevan los compromisos inherentes a la figura de una "ama de casa" común y corriente. Parecería que la poeta escupe sobre cada labor doméstica que, seguramente, ha cumplido hasta el cansancio, hasta el punto de dislocar el funcionamiento de la lógica convencional y producir un realismo mágico expreso que la salva de la monotonía. Al respecto, la crítica Maylen Sosa apunta que "[l]a voz poética denota un cansancio, un agotamiento por el rol o posición pasiva a la que por mucho tiempo estuvo forzada la mujer, y señala la ruptura progresiva con el antiguo esquema" (Sosa, 2006: 65). Ya el simple mohín de comenzar su poema con letra minúscula delata su resistencia a seguir, incluso, los preceptos gramaticales. Ella misma es capaz de generar su propio alfabeto para escribir acerca de lo que, en definitiva, le interesa decir.

La burla, la ironía y la alucinación hacen su entrada y se instalan a vivir en el poema. Son, como señala el crítico Enrique Arenas Capiello, el resultado "de un hondo y detenido trabajo desde el texto mismo, desde el arduo esfuerzo con las palabras, la sintaxis y los tonos" (Arenas, 2007: 40). Franco, entonces, se hace justicia desde la palabra que ella misma enhieste, en un fiero impulso de refugiarse lejos de la rutina. Arenas sabe apreciarla en su exacta dimensión intelectual cuando afirma que "[s]u eficacia, originalidad y talento consisten más bien en extremar zonas de lo real, tensar su ámbito de forma que se logre revelar y transfigurar su materia, sus elementos, su facticidad. Poesía más que solamente de lo fáctico es, fundamentalmente, de lo posible, de lo virtual escondido en la realidad obvia y ordinaria" (p. 40). El crítico cita, más adelante, otros versos de Franco en los que la podemos sorprender en una actitud hostil a todo determinismo ancestral, pues en su clima personal quiere vivir -nadar- a 
contracorriente del estigma de comportarse como una mujer "normada" por el peso de "la costumbre". Los versos extraídos por Arenas son éstos:

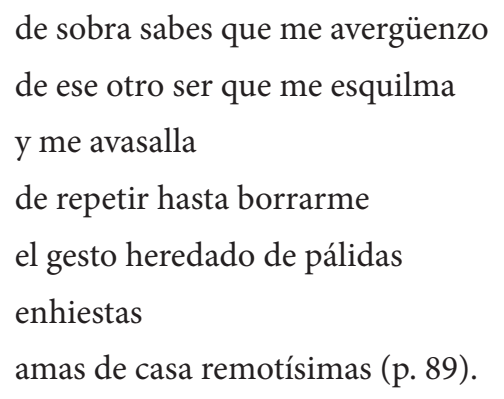

A este extracto poético deseo añadir otros versos que se encuentran en el mismo texto, porque, a mi juicio, ponen en evidencia el alto grado de madurez alcanzado por Franco en lo que se refiere a su experiencia de vida y a la precisión lograda en su justa representación verbal:

ten en cuenta muchacho de las cavernas que he ido ganando el derecho a perder de igual a igual el paraíso la paciencia a compartir la cama el santo y seña el mundo fifty fifty

o no hay trato

vete acostumbrando hombre voraz mujer no es sólo receptáculo

flor que se arranca

y herida va a doblarse en el florero

al fondo de la repisa

entre santos y candelabros y trastos de cocina una mujer es una mujer más sus uñas y sus dientes lo siento caballero de la brillante armadura aquesta doncella rompió el molde creció (p. 90).

El poema final de Una posee un título homónimo del mismo, en el que Franco parodia los hábitos domésticos y las actitudes que la mujer casada pone en práctica dentro del recinto asfixiante de la casa, al mismo tiempo que da una lección del correcto empleo del pronombre personal "una", a modo de reivindicación de un uso gramatical que había quedado sepultado con la imposición del pronombre neutro -y, por lo tanto, unisex- "uno". Por eso, la poeta resalta la palabra UNA con mayúsculas. Una vez más, volvemos a encontrar -ya se vio en la poesía de Castellanos- de qué manera, por debajo de los dictámenes domésticos, existen grietas que amenazan con quebrantar el "orden-ordinario", y esas grietas son las que surgen de la seducción entre mujer y libros, mujer y palabra, mujer y poesía:

\section{UNA amanece}

con el cuerpo de cera

con la víspera haciendo piruetas

con ojeras que delatan los retorcimientos del amor

UNA sabe que tiene prejuicios

y los va perfeccionando

UNA es a-política

UNA no se mete en camisa de once varas

UNA estampa el beso curricular

ÉL se va con sus ínfulas

con su ontológica suficiencia

UNA comparece ante el tribunal de los hijos

y cede ante la tiranía de los hijos

UNA tiene el deber de ser bella

porque entre otras cosas para eso está UNA

y para comprar lo que nos vendan

y para sufrir por la muchacha de la telenovela

que es tan desgraciada (la muchacha y la

telenovela)

y para llorar de felicidad porque al final

el sapo se convierte en magnate y se casa con

ELLA

UNA es tan sentimental

UNA es tan fiel tan perrunamente fiel 
que asquerosamente fiel es UNA

UNA se asoma al espejo y comprueba lo que no es

sabe qué cara va a poner

qué silencio va a arriar

qué píldora de domesticidad va a tener que tragarse

qué anticonceptiva es UNA

UNA queda tendida

knock out

para reaparecer al día siguiente

pidiendo la revancha (pp. 103-104).

La dedicatoria del poema ya es, de por sí, elocuente: "a mis congéneres y a ellos aunque mal paguen". La ironía del tono que elige Franco para construir su universo poético es uno de los tropos más fuertes que lo atraviesan; burla fina de un genio con garbo que se aviene, perfectamente, con el estilo característico del contexto marabino, en el cual lo dicho -con base en hipérboles- siempre tiene un sentido contrario como verdadera intención. Sosa lo refiere en estos términos: "La ironía en este discurso es un elemento que otros críticos también han percibido, y que funciona como recurso esencial para zaherir en la expresión de sus críticas y cuestionamientos" (Sosa, 2006).

Según un estudio realizado por Ana María Romero, en el que se revisa la poesía de Lydda Franco desde el enfoque del análisis del discurso, la crítica llega a concluir que "[1]a ironía discursiva tiene la función pragmática de estimular el espíritu crítico o la confrontación de ciertas posturas ideológicas de quien lee" (Romero, 2006: 134). En cuanto a su estilo, Romero afirma que "[l] a poesía de Franco Farías puso de relieve una voz femenina cuyo ejercicio poético, desde los inicios, se caracterizó por la ruptura con ese modelo de poesía intimista, de sensualidad sutil y la introspección, para destacar la ironía y la oralidad" (p. 142). Estos dos últimos elementos forman la base sobre la que se levantan los variados actos de habla registrados por Franco, en su diario discurrir.

\section{María Mercedes Carranza y Piedad Bonnet} Resta por abordar la contribución al tema de lo doméstico de dos excelentes poetas colombianas: María Mercedes Carranza y Piedad Bonnet. La primera de ellas, quien lamentablemente se suicidó, posee un libro cuyo título es emblemático: Tengo miedo. En el poema homónimo, ya no hallamos la postura rebelde de una Lydda Franco Farías que se mofa del canon doméstico, sino el espacio de la casa transformado en un ente terrorífico que agobia a la poeta. Ni siquiera el refugio en la palabra alivia su desazón, como pasa con sus compañeras de oficio:

Miradme: en mí habita el miedo.

Tras estos ojos serenos, en este cuerpo que ama: el miedo.

El miedo al amanecer porque inevitable el sol saldrá y

he de verlo, cuando atardece porque puede no salir mañana. Vigilo los ruidos misteriosos de esta casa que se derrumba, ya los fantasmas, las sombras me cercan y tengo miedo.

Procuro dormir con la luz encendida

y me hago como puedo a lanzas, corazas, ilusiones.

Pero basta quizás sólo una mancha en el mantel

para que de nuevo se adueñe de mí el espanto.

Nada me calma ni sosiega:

ni esta palabra inútil, ni esta pasión de amor, ni el espejo donde veo ya mi rostro muerto.

Oídme bien, lo digo a gritos: tengo miedo (Carranza, 2003: 67).

En otro poema suyo titulado "Situaciones", Carranza nos acerca una pista de lo que pudiera ser el origen de su sobrecogimiento: haber vivido su infancia bajo una vigilancia materna rígida $y$ castigadora. Veamos: 
Del miedo: una niña de cuatro años

está jugando con un tintero,

la tinta se derrama sobre el tapete.

La madre se le acerca a pegarle.

Los ojos de la niña se abren más de lo normal

y expresan desconcierto y temor.

Esos mismos ojos, treinta años después,

me están mirando ahora en el espejo (pp. 71-72).

Otro de los poemas finales, "El oficio de vestirse", subraya el peso desquiciante que la rutina $y$ la educación familiar han ejercido sobre la poeta, una situación que la hace estar fuera de sí porque consigue verse en la actitud compulsiva de acatar y atacar quebrantando leyes morales, sociales y conyugales. La crítica Patricia Valenzuela lo resume de este modo: "Carranza echa mano de lo cotidiano como de una pesada ancla" (Valenzuela, 1998: 22).

De repente,

cuando despierto en la mañana

me acuerdo de mí,

con sigilo abro los ojos

y procedo a vestirme.

Lo primero es colocarme mi gesto

de persona decente.

Enseguida me pongo las buenas

costumbres, el amor

filial, el decoro, la moral,

la fidelidad conyugal:

para el final dejo los recuerdos.

Lavo con primor

mi cara de buena ciudadana

visto mi tan deteriorada esperanza,

me meto entre la boca las palabras,

cepillo la bondad

y me la pongo de sombrero

y en los ojos

esa mirada tan amable.
Entre el armario selecciono las ideas

que hoy me apetece lucir

y sin perder más tiempo

me las meto en la cabeza.

Finalmente

me calzo los zapatos

y echo a andar: entre paso y paso

tarareo esta canción que le canto

a mi hija:

"Si a tu ventana llega

el siglo veinte,

trátalo con cariño

que es mi persona” (p. 75).

También en "Conversación con mi hija”, la poeta deja entrever -con ironía- el modo en que las costumbres impuestas de generación en generación van mutilando a la mujer, hasta convertirla en una máquina repetidora de hábitos y ademanes, con derecho a un solo sentimiento: el miedo. Lo vemos claramente en los últimos versos del poema: "Usa siempre la cortesía y / no se te olvide, hija, / lavarte los dientes todas las mañanas / y apagar la luz antes de dormir" (Carranza, 2003: 83).

Por último, le damos la palabra a Piedad Bonnet. En el poema-dedicatoria que Bonnet le dirige "Al lector" en su primer libro, De círculo y ceniza (1996), asombra la cercana correspondencia al sentimiento de miedo que azola a su coterránea, María Mercedes Carranza. En efecto, el texto se inicia con estos versos:

¿Esto era todo?

¿Esto que nos han dado?

Planchas viejas, botones sin ojal,

lámparas rotas,

una ventana inútil,

tanto viento,

unos ojos de vidrio, un bastón hueco,

y palabras, palabras...

Nos dijeron:

No hay que llorar en público, 
y menos maldecir.

¡Paciencia, hermanos!

Mi madre me dio un beso,

pero apagó la luz (Bonnet, 1996: 1).

En el poema final del libro, el título "Diario" hace explícita su intención. Respondiendo al sentido de síntesis que se espera de toda creación poética, Bonnet elabora el catálogo de su vida en densas fracciones vitales que expresan su identidad más íntima, la formación de hogar que ha recibido -lo expresa irónicamente- al pie de la letra:

Dicen que el tiempo es oro

y que hay que hacer, hacer sin darse tregua.

Remordimientos no tengo ninguno:

hice una enorme torta con diez huevos

y con detalles escribí una carta.

De madrugada y minuciosamente

hice el amor con gran desenvoltura

y gran concentración.

Cien páginas leí de una novela que ilustra las pasiones de una viuda.

Y ahora, frente al espejo solitario

que irremediablemente me duplica,

escupo el tedio, escupo la mentira,

saco la lengua blanca y hago un gesto (p. 54).
En ambos textos, los hábitos domésticos afloran como un hilo conductor. En este sentido, Clara Eugenia Ronderos, quien prologa el poemario citado, afirma que

[L]os oficios domésticos reaparecen una y otra vez en su obra como metáforas diversas de la vida: algunos poemas los presentan como una muerte sosa que lleva ésta a su interior; como una hipocresía que oculta los vicios de su esterilidad; como un momento sublime en el que la vida se presenta sin máscaras, de la manera más obvia y más hermosa (p. IX).

Pensando específicamente en los poemas extraídos, me inclino a pensar -con Ronderos- que en ellos hay "un gesto de hastío ante la vida cotidiana".

La percepción que, en conjunto, las poetas registran en torno a la manera de asumir el espacio de la casa en todo lo que ella implica (enseres -todas, menos Calcaño, aluden al espejo-, hábitos, leyes, horarios, rituales, etc.), me permite concluir que es posible construir una poética de la vida doméstica cuyo péndulo oscila entre el encanto y el desencanto, entre el acato y el repudio, en una compleja gama de posibilidades que las convierte, a todas ellas, en fuertes portavoces de la sensibilidad y los saberes que caracterizan a la mujer latinoamericana de los siglos XX y XXI. П 


\section{Referencias bibliográficas}

Arenas, E. (2007). El Disparate y el Enigma / Dislocación, Ritual, Absurdo en La poesía de Lydda Franco Farías. Revista de Literatura Hispanoamericana, 54.

Armstrong, N. (1987). Deseo y ficción doméstica. Una historia política de la novela. Madrid: Cátedra.

Bonnet, P. (1996). De círculo y ceniza. Bogotá: Ediciones Uniandes.

Boscán de Lombardi, L. (1998). La poesía de María Calcaño. Revista de Literatura Hispanoamericana, 37.

Calcaño, M. (1983). Antología poética. Maracaibo: Editorial de la Universidad del Zulia.

Carranza, M. M. (1995). De amor y desamor. Bogotá: Norma.

Carranza, M. M. (2003). Tengo miedo. Bogotá: El Áncora Editores.

Castellanos, R. (2002). Poesía. México: Universidad Nacional Autónoma de México.

Domínguez Torres, M. (2007). La representación de las mujeres en la prensa venezolana. Maracaibo: Ediciones del Vicerrectorado Académico. Universidad del Zulia.

Domínguez, N. y Perrilli, C. (Comps.). (1998). Fábulas del género. Sexo y escritura en América Latina. Buenos Aires: Beatriz Viterbo Editora.
Franco Farías, L. (2002). Antología poética. Coro: Universidad Nacional Experimental Francisco de Miranda-Dirección de Cultura-Fondo Editorial del Estado Falcón, Incudef.

Gil Iriarte, M. L. (1996). "La voz a ella debida”: la imagen de la mujer en la poesía de Rosario Castellanos. Revista de Literatura Hispanoamericana, 32.

Litvak, L. (1979). Erotismo de fin de siglo. Barcelona: Casa Editorial Bosch.

Mandrillo, C. (2008). Relectura de la obra poética de María Calcaño. Espéculo, 39.

Masiello, F. (1997). Entre civilización y barbarie. Mujeres, Nación y Cultura Literaria en la Argentina moderna. Buenos Aires: Beatriz Viterbo.

Romero, A. M. (2006). Oralidad y alienación femenina en la poesía de Lydda Franco Farías. Única. Revista de Artes y Humanidades, 16.

Sosa Silva, M. (2006). Exploración de líneas de significación en la poesía de Lydda Franco Farías: la enunciación de lo femenino. Revista de Literatura Hispanoamericana, 52.

Suardíaz, L. (1999). María Calcaño, la radiante desconocida. Revista de Literatura Hispanoamericana, 38.

Valenzuela, P. (1998). María Mercedes Carranza. Balance inicial. Boletín Cultural y Bibliográfico, 47. 